
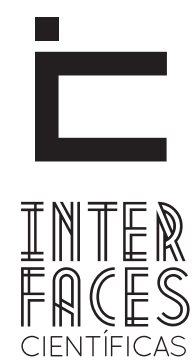

HUMANAS E SOCIAIS

\title{
EXPRESSÃO SOCIAL: UM CRUZAMENTO ENTRE A PALAVRA E O CONTEXTO DE PRODUÇÃO DO DISCURSO
}

Thiago Soares de Oliveira ${ }^{1}$

\section{RESUMO}

Como resultado da análise teórica e prática de alguns cartazes expostos durante as manifestações ocorridas no Brasil em 2013, este artigo propõe uma reflexão interdisciplinar acerca de como a inscrição da língua em determinado contexto de produção do discurso pode elevá-la à expressão da ideologia que, sustentada pelas características que compõem o enunciado, materializa a comuni- cação social. Para isso, articularam-se os pressupostos teóricos de Bakhtin (2009) aos de outros autores que discutem a respeito do emprego da língua como prática social.

\section{PALAVRAS-CHAVE}

Campo discursivo. Signo linguístico. Expressão social. 


\section{ABSTRACT}

As a result of the theoretical and practical analysis of some posters displayed during the protests that occurred in Brazil in 2013, this article proposes an interdisciplinary reflection about how the inclusion of language in a particular context of discourse production can raise it to the expression of the ideology, sustained by the characteristics that make the statement, materializes the

\section{RESUMEN}

Como resultado del análisis teórico y práctico de algunos carteles expuestos durante las manifestaciones que tuvieron lugar en Brasil en 2013, éste artículo propone una reflexión interdisciplinaria de como la inscripción del lenguaje en un contexto particular de la producción del discurso, puede elevarlo a la expresión de la ideología, que sostenida por las características que hacen la declaración, materializa los medios social communication. For this, we articulated the Bakhtin's theoretical assumptions with another authors who discuss about the use of language as a social practice.

\section{KEYWORDS}

Discursive field. Linguistic sign. Social expression.

de comunicación. Para ello, se han articulado las suposiciones teóricas de Bakhtin (2009) a otros autores que discuten acerca de la utilización del lenguaje como práctica social.

\section{PALABRAS CLAVE}

Campo discursivo. Signo linguístico. Expresión social. 


\section{PRIMEIRAS CONSIDERAÇÕES}

Durante o ano de 2013, o Brasil foi palco de inúmeras manifestações populares em prol de necessárias mudanças nos alicerces sobre os quais a sociedade brasileira se sustenta. Milhares de cidadãos, alijados de seus direitos e sujeitos a serviços públicos de qualidade duvidosa, saíram às ruas e fizeram ressoar a voz de uma nação que, adormecida, parecia despertar para o advento de novos tempos, quando o eco da massa popular passaria a ser ouvida pelos burocratas e representantes eleitos democraticamente.

Em meio às reivindicações, iniciadas graças à insatisfação geral com as tarifas abusivas cobradas pela utilização de um transporte público deveras precário, destacava-se o clamor pelo investimento em educação e saúde de qualidade, em segurança pública e pelo combate à corrupção. Inúmeros foram os cartazes que ilustraram os protestos e reforçaram o caráter ideológico das manifestações, especialmente no que diz respeito à educação. Palavras de ordem e pedidos representativos de transformação social inundaram as ruas e aqueceram as discussões políticas acerca da conduta a ser adotada em uma clara situação de crise.

Nesse cenário, as palavras ficaram destituídas da simples obrigação de comunicar, revestindo-se de função social cujo entendimento só pode ser alcançado se considerado o contexto em que elas foram produzidas. As normas gramaticais foram empregadas em outro patamar de significação, servindo de esteio à expressão ideológica que se quis atingir. Os produtores dos discursos, apoiados na estruturação ortográfica propositada, exprimiram suas intenções e descontentamentos, bem como reclamaram mudanças urgentes.

Assim, dada à profundidade de tais discussões acerca de como a palavra se eleva a estatuto ideológico a depender do contexto em que é utilizada, não se pretende exaurir as vias de análise dos cartazes escolhidos como corpora deste trabalho, tampouco promover uma reflexão puramente sociológica, mas ponderar sobre como a interrelação mantida entre a palavra, considerada como signo ideológico, e o contexto de produção do discurso pode produzir expressão social com auxílio de mecanismos da norma da língua.

\section{BREVES COMENTÁRIOS SOBRE SIGNO LINGUÍSTICO, ENUNCIADO (DISCURSO) E EXPRESSÃO IDEOLÓGICA}

Contrariamente ao entendimento firmado pelo senso comum, língua e linguagem não são palavras sinônimas para o campo dos estudos linguísticos. Essa distinção é promovida a partir da relação de abrangência entre uma e outra, sendo a linguagem, de forma mais ampla, "a capacidade específica da espécie humana de se comunicar por meio de signos" (FIORIN, 2013, p. 13), como forma de resposta a uma necessidade natural: a da comunicação. De modo mais restrito, "a língua é um sistema de signos específicos aos membros de dada comunidade" (FIORIN, 2013, p. 14).

Em Saussure, a língua é campo de especial interesse por ser considerada social e coletiva, diferentemente da fala, que é entendida como individual e particularizante. Ocorre que, apesar de considerar que "a língua é elaborada pela comunidade, é somente nela que ela é social" (CALVET, 2002, p. 16), o linguista não fornece bases teóricas para justificar o fato de considerar a língua como uma instituição social, limitando-se a declarações que "chocam por sua indefinição teórica” (CALVET, 2002, p.15). Em razão disso, ainda que não se possam negar as contribuições do linguista genebrino, este trabalho não se apoiará em sua obra Curso de Linguística Geral.

Ao refletir sobre o objeto da Linguística, Fiorin (2013, p. 47) explica que "Saussure compara a lingua- 
gem a um jogo de xadrez", sendo que o jogo constituiria o sistema regular e invariante, ao qual importariam apenas as peças e as regras. A esse sistema Saussure denominou langue (língua) - seu foco de estudo - em oposição ao que chamou de parole (fala), caracterizada como "variável, concreta, real, individual” (FIORIN, 2013, p. 50).

Apesar disso, o conceito de signo linguístico proposto pelo estruturalismo ${ }^{3}$ de Saussure, como uma imagem acústica (significante) que remete a um conceito (significado), é amplamente explorado pelos estudiosos da linguagem, que dele se valem como ponto de partida para as análises relativas aos significados que podem ser impressos às palavras dependendo do contexto discursivo em que são produzidas. Isso significa que a forma linguística deve ser percebida como um signo mutável, já que este é, "por natureza, vivo e móvel, plurivalente" (BAKHTIN, 2009, p 15).

A mutabilidade do signo linguístico pode ser notada tanto em relação ao significante quanto em relação ao significado. Mudanças propositadas na disposição das letras que compõem um significante podem produzir um novo significante, o qual, por sua vez, gera um novo significado, mais amplo ou mais restrito, conforme a intencionalidade do produtor do discurso em que o signo, vivo, é inserido.

Nesse sentido, "o discurso é um produto social, resultante da enunciação" (DISCINI e FIORIN, 2013, p. 184) e se manifesta por meio do texto, este "como um modo de naturalizar e vulgarizar realidades sociais, como instrumento de autoridade, e como o meio (e a medida) da disputa política" (HANKS, 2008, p. 153). Com efeito, o discurso se aproxima do uso social que é dado à língua e tem um propósito que supera a signifi-

3. De forma sucinta, ao estruturalismo de Saussure, em termos linguísticos, interessava "descrever num determinado estádio da língua (isto é, sincronicamente), as unidades pertencentes aos diversos níveis da língua (fonemas, morfemas, etc.), sua posição no sistema e suas regras combinatórias. Foi essa a razão pela qual, durante o estruturalismo [...], a fonologia e a morfologia tiveram grande desenvolvimento" (KOCH, 2012, p. 8). cação primeira que um enunciado aparenta apresentar, servindo como meio de atingir um efeito.

Acerca disso, explica Maingueneau (2004, p. 19-20):

Considera-se, geralmente, que cada enunciado é portador de um sentido estável, a saber, aquele que the foi conferido pelo locutor. [...] A reflexão contemporânea afastou-se dessa concepção da interpretação dos enunciados: o contexto não se encontra simplesmente ao redor de um enunciado que conteria um sentido parcialmente indeterminado que o destinatário precisaria apenas especificar. Com efeito, todo ato de enunciação é fundamentalmente assimétrico: a pessoa que interpreta o enunciado reconstrói seu sentido a partir de indicações presentes no enunciado produzido, mas nada garante que o que ela reconstrói coincida com as representações do enunciador.

Essa reconstrução de sentido é, a rigor, proporcionada pelo contexto de produção do enunciado ${ }^{4}$, conceituado por Maingueneau (2004, p. 57) como "o valor de frase inscrita em um contexto particular". Em razão da análise que se pretende a respeito de como o contexto de produção pode elevar a língua à expressão da ideologia, optou-se, neste trabalho, por utilizar o termo discurso, "ou seja, a língua em sua integridade concreta e viva, e não a língua como o objeto específico da linguística, obtido por meio de uma abstração absolutamente legítima e necessária de alguns aspectos da vida concreta do discurso" (BAKHTIN, 2013, p. 207).

Não obstante, não se intenciona adentrar com profundidade no campo de estudo da Semiótica, "que busca estudar a significação independentemente da maneira como ela se manifesta" (DISCINI e FIORIN, 2013, p. 184), por ser demasiado amplo em relação ao que anseia este artigo e por demandar uma investigação teórica que extrapola o objetivo de análise sucinta do contexto de produção do discurso aqui proposto.

Nessa linha expositiva, é importante explicar que,

4. Enunciação seria o ato de enunciar, isto é, a evocação crítica de um enunciado. 
[...] contexto é um conceito teórico, estritamente baseado em relações. Não há contexto que não seja 'contexto de', ou 'contexto para'. Como esse conceito é tratado depende de como são construídos outros elementos fundamentais, incluindo língua(gem), discurso, produção e recepção de enunciados, práticas sociais, dentre outros". (HANKS, 2008, p. 174).

Relativamente à expressão ideológica que impregna o discurso, Bakhtin (2009. p. 31) afirma que "tudo que é ideológico possui um significado e remete a algo situado fora de si mesmo", relacionando a ideologia ao signo linguístico de tal forma que "sem signos não existe ideologia” (BAKHTIN, 2009, p. 31). Isso significa que os signos emergem na consciência individual por meio da interação social, que só possível através da palavra5", isto é, "um material flexível, veiculável pelo corpo” (BAKHTIN, 2009, p. 37).

Nessa ótica, o fenômeno ideológico é produzido pela linguagem ${ }^{6}$, mais precisamente pela palavra, em razão da capacidade de representar uma realidade social. Assim, "o processo de simbolização da linguagem exige um sistema fonético que articule imagens acústicas 'gerando' o símbolo, o qual proporcionará condições para a produção de conceitos/pensamentos" (SEVERO, 2004, p. 128). Para Orlandi (2010, p. 96), a ideologia é "mecanismo estruturante do processo de significação", o qual "se liga inextricavelmente à interpretação enquanto fato fundamental que atesta a relação da história com a língua, na medida em que esta significa”.

Por fim, há de se observar que essa articulação entre a palavra e a ideologia é possível graças à existência do signo linguístico inscrito na realidade social, afinal não se pode "entrar no domínio da ideologia, tomar forma e aí deitar raízes senão aquilo que adquiriu um valor social” (BAKHTIN, 2009, p. 46).

\footnotetext{
5. Bakhtin (2009, p. 38) elenca em Marxismo e Filosofia da Linguagem as propriedades que fazem da palavra "o objeto fundamental para o estudo das ideologias”, quais sejam: pureza semiótica, neutralidade ideológica, implicação na comunicação humana ordinária, possibilidade de interiorização e presença obrigatória em todo ato consciente.

6. Hjelmslev (1975 apud FIORIN, 2013, p. 14) afirma que "a linguagem é o instrumento graças ao qual o homem modela seu pensamento".
}

\section{REFLEXÕES SOBRE AS IMPLICAÇ̃̃ES DO CONTEXTO DE PRODUÇÃO NO DISCURSO SOCIAL}

Partindo do contexto das manifestações ocorridas no ano de 2013, as palavras - que ilustram os cartazes selecionados como corpora, para este trabalho - serão analisadas na tentativa de demonstrar que, na verdade, constituem muito mais que um aglomerado de signos linguísticos saussurianos, emanando posições ideológicas perceptíveis se considerados os contextos em que elas foram produzidas. Eis a Figura 1:

Figura 1 - A questão ortográfica

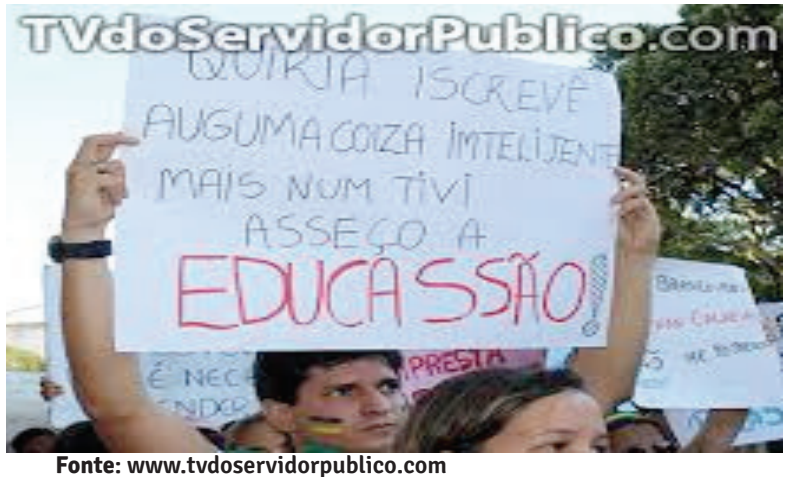

Considerando o conceito de signo em Bakhtin e a premissa de que "tudo que é ideológico é um signo" (BAKHTIN, 2009, p. 31), é possível notar como as palavras empregadas na figura acima suplantam a mera definição de signo linguístico proposta por Saussure, ou seja, o resultado da união entre significante e significado, já que elas, muito acima da individualidade de cada uma, refletem a realidade em transformação, corroborando a noção de que a existência do signo materializa o que se quer comunicar socialmente.

A princípio, o emprego dos vocábulos em evidente desacordo com a norma ortográfica padrão destacar-se no contexto de revolta popular em que foi proposto, na 
medida em que essa questão descortina a intencionalidade clara de um dos pontos-chave da manifestação: a preocupação com a educação. Por isso, não surpreende o destaque que foi dado à palavra "EDUCASSÃO". Isso significa que as palavras empregadas não constituem desvio genuíno de norma, pois estão revestidas de um fundo ideológico que se sobrepõe à realidade ortográfica do cartaz, evidenciando que a "palavra é um fenômeno ideológico por excelência" (BAKHTIN, 2009, p. 36), capaz de expressar uma relação social.

Nessa direção, a contraposição entre educação e "educassão" representa, de forma ideológica, respectivamente a educação acessível que se gostaria de ter, capaz de dar aos indivíduos conhecimento para se expressar diante daquilo que não lhes agrada e daqueles que não os representam, e a "educassão" que se tem: falha, despreocupada e inacessível. 0 que ocorre na Figura 1, entretanto, é que quem a manejou se valeu conscientemente de um dos aspectos da própria realidade educacional, representada pelos desvios ortográficos, para tecer uma forte e pertinente crítica à atenção, dispensada à educação brasileira.

Tomando como pressuposto o legado de Bakhtin (2009), o discurso social contido no cartaz pode ser relacionado às noções de infraestrutura e superestrutura. Basta analisar o sentido em que é tomado o vocábulo "educassão", como representante do sistema educacional que se acredita estar instalado no país, ou seja, como a realidade educacional em si (infraestrutura) que, tomada como signo ideológico (superestrutura), e não como um desvio de norma, deveria ser convertida em educação. Logo, desconectada de um contexto social, "educassão" não passaria de um equívoco ortográfico ou erro de escrita. Contudo, ao ser imersa no ambiente da manifestação, a expressão comunica muito mais que um desvio, alcançando a ideia sobre a realidade, isto é, ideologia, como se a dicotomia educação x educassão representasse, de fato, a educação que se pretende e aquela a que se tem acesso.

Nessa ótica, o modo como é empregada a palavra no discurso específico pode elevá-la ao status de pro- dutora de "[...] lentas acumulações quantitativas de mudanças que ainda não tiveram tempo de engendrar uma forma ideológica nova e acabada" (BAKHTIN, 2009, p. 42), demonstrando que, associada a contextos sociais diversos, a palavra adotará significações também diversas, as quais não devem ser desvinculadas do propósito ideológico que as reveste.

De forma também propositada, a Figura 2 (a seguir exposta) emprega vocábulos em aparente desacordo com a norma padrão ${ }^{7}$. Contudo, diferentemente do que ocorre na Figura 1, os pontos enfáticos do discurso são intencionalmente marcados pelas aspas, significando que

[...] os dizeres não são [...] apenas mensagens a serem decodificadas. São efeitos de sentidos que são produzidos em condições determinadas e que estão de alguma forma presentes no modo como se diz, deixando vestígios que o analista do discurso tem de apreender. (ORLANDI, 2010, p. 30).

\section{Figura 2 - Destaque marcado aos desvios de norma}

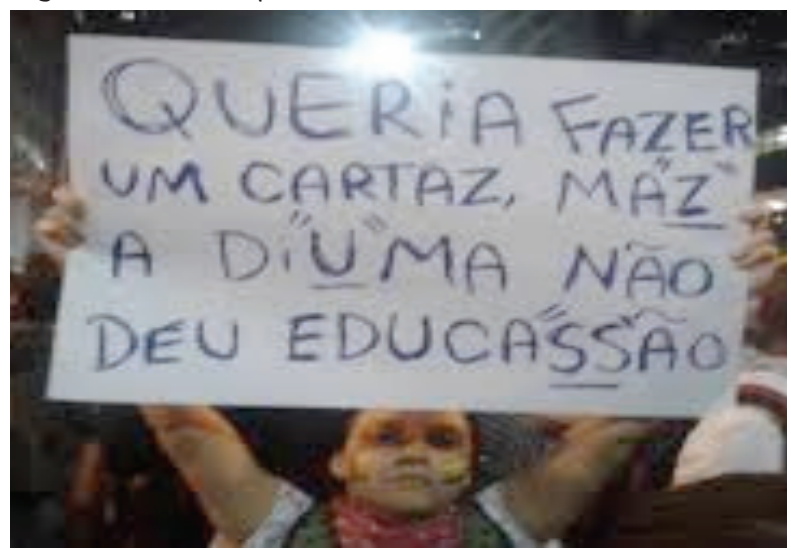

Fonte: www.paroutudo.com

Na figura 2, o indivíduo que produziu o discurso no contexto das manifestações populares optou pela

\footnotetext{
7. Bagno (2007) prefere a expressão norma padrão à norma culta, pois considera que, se ambas fossem sinônimas, o falantes considerados cultos conheceriam e aplicariam o que é chancelado como padrão normativo. 0 que ocorre, entretanto, é que os falantes ditos cultos não falam ou escrevem exatamente conforme as previsões da gramática normativa, revelando que, mesmo os indivíduos mais escolarizados e mais urbanos, considerados cultos, não seguem à risca o padrão que lhes é imposto.
} 
marcação dos pontos-chave a que pretendia fazer alusão, sendo que a primeira marcação é, em princípio de análise, mais ortográfica que as demais. Afirma-se isso porque, na verdade, há na palavra "ma'z"' um discurso político em favor da educação, o qual pode ser facilmente compreendido no contexto em que foi produzido e corroborado pelas próximas marcações com as aspas.

No entanto, o vocábulo em questão, de per si, não evoca o social, senão quando imerso no contexto das manifestações. De forma isolada, o primeiro vocábulo marcado nada mais seria que uma conjunção ${ }^{8}$ coordenativa adversativa grafada em desconformidade com as normas ortográficas vigentes, mas, por estar imerso em um contexto claramente social, tal vocábulo tem seu status alterado, passando a signo, porque:

[...] é criado por uma função ideológica precisa e permanente inseparável dela. A palavra, ao contrário, é neutra em relação a qualquer função ideológica específica. Pode preencher qualquer função ideológica: estética, científica, moral, religiosa. (BAKHTIN, 2009, p. 37).

Analogamente, essa alteração do status de mera palavra, passando a signo, também, ocorre em relação à segunda marcação, na qual o caráter político se revela com maior nitidez, uma vez que o destaque que se pretendeu dar ao desvio de norma recaiu sobre o nome ${ }^{9}$ de uma representante eleita democraticamente, no caso de "Di'u'ma". De forma semelhante, a terceira palavra, cujo desvio propositado recebeu as aspas ("educa'ss'ao"), é o cerne da questão que impulsionou o enunciador a levantar o cartaz. Isso significa que, tomadas individualmente, ambas as palavras carregam em si mesmas uma potencial discussão política que toma forma no cenário em que elas foram produzidas.

Logo, a questão da marcação gráfica dos desvios revela que "cada signo ideológico é não apenas um

\footnotetext{
8. A gramática normativa classifica a palavra, mas como conjunção. Em termos puramente classificatórios, o normativismo não estaria apto a identificar a expressão ideológica no vocábulo em razão da preocupação prescritivista que lhe é inerente.

9. Nota-se que o nome é, em outras palavras, um antropônimo, já que "Di‘u'ma" é grafado com letra inicial maiúscula, em referência à Presidenta da República.
}

reflexo, uma sombra da realidade, mas também um fragmento material dessa realidade" (BAKHTIN, 2009, p. 33), que, assentado na criatividade do enunciador, reflete a comunicação social pretendida, produzindo efeitos próprios no contexto em que ocorreu, uma vez que "a linguagem só faz sentido porque se inscreve na história” (ORLANDI, 2010. p. 25).

Em perspectiva similar, a Figura 3 também ilustra que o texto é "um modo poderoso de naturalizar a realidade social” (HANKS, 2008, p. 152), mas utilizando-se da questão fonética ${ }^{10}$ para revelar uma assimetria social que encontra respaldo no contexto de produção do discurso.

\section{Figura 3 - A questão fonética}

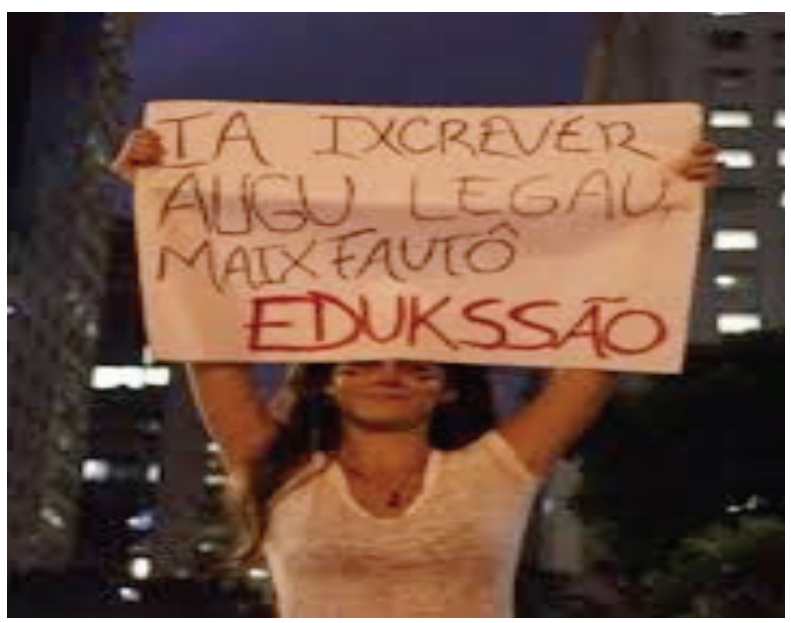

Fonte: www.vejasp.abril.com.br

A escrita contida na figura acima, longe de se tratar de desvio típico de norma, retrata um choque normativo, uma vez que as palavras são grafadas da forma como provavelmente seriam pronunciadas pelo criador do cartaz, aparentemente desconsiderando que há “diferença entre a língua falada e a língua es-

\footnotetext{
10. Optou-se pela noção de Fonética em vez da de Fonologia porque, segundo Sacconi (2001, p. 22), esta "estuda os sons da língua”, enquanto aquela, "os sons da fala". Além disso, não seria possível a alusão a situações normativas sem que, de alguma forma, fossem utilizados conceitos também normativos, embora este não seja o foco deste trabalho.
} 
crita, dois meios de comunicação diferentes" (NICOLA E INFANTE, 1997, p. 19).

Não obstante tal aparente aspecto de ignorância à norma escrita, a questão fonética foi articulada com uma finalidade maior que a normativa, já que o efeito oriundo do cartaz decorre de uma suposta interpretação do binômio certo/errado relacionado à fala e à escrita, apregoado pela gramática. Logo, vale observar que é com base na noção de que não se deve escrever da forma que se fala que o discurso do cartaz atinge seu objetivo precípuo. Isso significa que "não há sentido sem interpretação e, além disso, diante de qualquer objeto simbólico o homem é levado a interpretar, colocando-se diante da questão: o que isto quer dizer?” (ORLANDI, 2010, p. 45).

Dessa forma, não se pode reduzir o discurso social que se apoia em palavras - tomadas como signos-, entretanto, a simples mecanismos gramaticais. Contudo, é preciso entender que tais mecanismos são o suporte que possibilita a interpretação da palavra como signo, e não como mero vocábulo destituído de significado social. Interpretar de forma reducionista, desconsiderando o fator ideológico que impregna o discurso e a sua propriedade de mutação significativa a depender do contexto social, é rejeitar que "a interação e a linguagem na interação são fenômenos de alta complexidade por envolverem múltiplos fatores em múltiplas relações" (FARACO, 2009, p. 143).

Outro aspecto que merece observação e que de fato representa a elevação da palavra ao status de signo é a questão sintática que, juntamente com a ortográfica e a fonética, destaca-se na Figura 4 conforme se pode observar a seguir. Por já terem sido explorados nos cartazes analisados anteriormente, não se discorrerá sobre as questões ortográfica e fonética na Figura 4, mas apenas sobre a sintática que se evidencia na relação de não concordância entre os sujeito "nois", representado por um pronome ${ }^{11}$ pessoal do caso reto, e o verbo "priciza”.

Figura 4 - A questão sintática

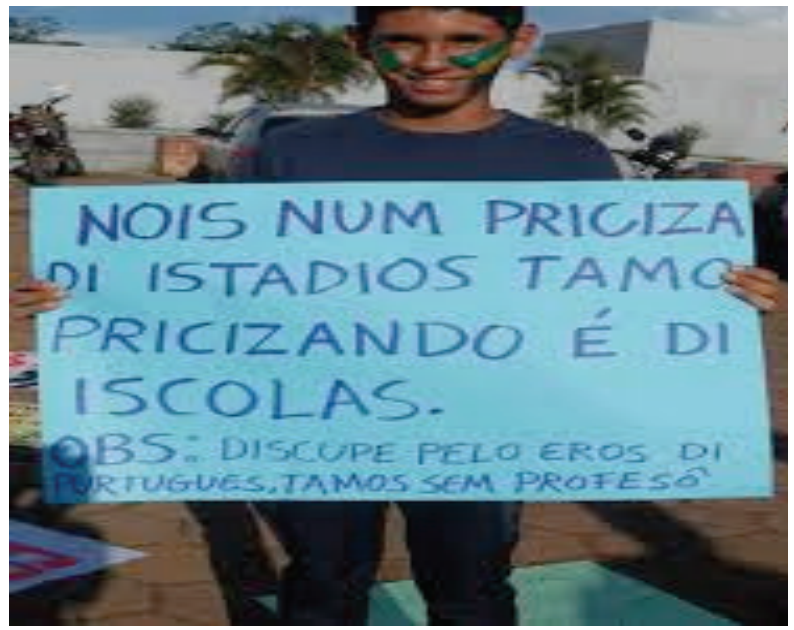

Fonte: www.permanecerecompartilhar.blogspot.com

Não fosse o contexto em que a combinação sintática foi apresentada, ela poderia ter inúmeras explicações, tais como a normativa ${ }^{12}$ e a linguística. No entanto, dado o contexto social de produção, o desvio na sintaxe ${ }^{13}$ de concordância chama a atenção ao aspecto educacional sem que, para isso, seja registrado um propositado desvio da palavra educação, como ocorreu em todos os corpora submetidos à análise. Nesse caso, o clamor pela educação de qualidade se manifestou ortográfica, fonética e sintaticamente.

\section{Relativamente à sintaxe da Língua Portuguesa,}

11. A gramática normativa classifica o vocábulo nós como pronome pessoal do caso reto. A Linguística do Discurso prefere a denominação proformas em vez de pronomes, já que essa categoria de palavras ora substitui, ora acompanha um nome.

12. O normativismo, considerado como o exame do fenômeno da linguagem efetuado pela gramática tradicional, também faz parte da linguística, tal como hoje é compreendida (WEEDWOOD, 2002). Optou-se aqui pela separação entre gramática e linguística apenas em razão do tratamento diverso que uma e outra dão à linguagem, bem como devido às reflexões propostas neste trabalho.

13. Sintaxe é a ordem linguística que se deve seguir na elaboração de uma frase ou oração, segundo Sacconi (2001). 
as gramáticas prescrevem como regra geral que o verbo deve concordar com o núcleo do sujeito a que está vinculado (NICOLA e INFANTE, 1997), o que não ocorre no registro do cartaz. A rigor, essa não concordância não decorre do desconhecimento ou do desprezo ao que é prescrito pelos compêndios gramaticais. Aliás, se assim o fosse, todos os fenômenos da linguagem estariam reduzidos ao tratamento da Linguística do Sistema ${ }^{14}$. Ao contrário, o efeito social produzido pelo discurso decorreu do conhecimento da regra geral de concordância, a qual foi manipulada para atingir o propósito de ilustrar a ausência e/ou precariedade da educação que se quer extirpar da sociedade.

Ocorre que, na Figura 4, "as formas do signo são condicionadas tanto pela organização social de tais indivíduos como pelas condições em que a interação acontece" (BAKHTIN, 2009, p. 45), estendendo-se às redes combinatórias propostas pela sintaxe. Assim, “cada signo linguístico possui seu tema”, este considerado como "a realidade que dá lugar à formação de um signo” (BAKHTIN, 2009, p. 46) e, sendo forma e tema indissoluvelmente ligados, quando a palavra se eleva a signo, veiculando ideologia, passa a "produzir evidências, colocando o homem na relação imaginária com suas condições materiais de existência" (ORLANDI, 2010, p. 46).

Em suma, “a ideologia não é a ocultação, mas função da relação necessária entre a linguagem e mundo" (ORLANDI, 2010, p. 47), o que desloca o simples desvio de concordância verbal a um propósito que se interrelaciona com aquilo que se pretende comunicar socialmente: a questão da educação e a necessidade de professores. Nesse último caso, o discurso contido no cartaz dá ao professor a condição de transmissor ${ }^{15}$ do saber, sem o qual

14. Expressão utilizada por KOCK (2012) para designar os princípios básicos da linguística moderna cuja paternidade é atribuída a Ferdinand de Saussure. 15. Como a discussão acerca do papel do professor no ensino da Língua não é pretensão deste trabalho, para maior aprofundamento sobre o tema, ler Ilari e Basso (2006), Nóvoa (1999), Perini (1985) e Soares (1986). os deslizes de norma não podem ser sanados, mais uma posição ideológica inscrita em um infinito de possibilidades interpretativas que o contexto de produção do discurso pode proporcionar.

\section{CONSIDERAÇÕES FINAIS}

Entendida como forma de expressão social, a língua, permeada pelo contexto discursivo em que se insere, abandona os rudimentos de mera exteriorização do pensamento que justificam seu uso, alcançando um patamar superior de comunicação social e ideológica, que pode ser experimentado conforme o contexto de produção. Os estudos de Bakhtin (2009) a propósito da concepção social do discurso e de como ele se constitui na interação são de suma importância para entender o aspecto mutável da língua, além de como seu emprego pode se estruturar de forma mais elevada, significando ideologia.

Nos cartazes selecionados como corpora para este trabalho, observou-se que o contexto das manifestações populares de 2013, que serviu de base para sua confecção, propiciou e impulsionou não apenas um amontoado comunicativo de palavras sem nexo contextual, mas um complexo jogo de palavras expressivo e ideológico que, com o suporte dos conhecimentos gramaticais manipulados propositadamente, foi capaz de evidenciar a capacidade articulatória múltipla das palavras. Estas, alteadas a signo, passam a evidenciar o desejo de mudança, não por meio de simples pedidos, mas de elaborados emaranhados que permitem o emprego da língua como prática social, levando a duas ilações complementares entre si, acerca do comportamento das palavras em um contexto específico, ainda que pareçam um tanto contraditórias.

A primeira conclusão a que se chega é a de que, devido ao forte apelo social dos cartazes no contexto de produção, as noções puramente gramaticais não são capazes de explicar o comportamento linguístico espe- 
cífico das palavras, porque não dispõe de mecanismos e propriedades flexíveis o suficiente para a incursão no campo da interrelação entre o social e o linguístico. As normas gramaticais, se aplicadas fora do contexto de produção específico do discurso, não se furtam da tendência classificatória e dicotômica que thes é inerente. Além disso, quando empregadas como suporte para o entendimento da elaboração da expressão social, tais normas ficam relegadas a papeis secundários e insuficientes do ponto de vista explicativo.

Apesar disso, as normas gramaticais sustentam um aporte teórico sem o qual não seria possível dar início à análise de corpora como os cartazes que foram selecionados. É a partir da suposta noção de erro e acerto que gravita em torno da gramática que se podem atingir os objetivos comunicativos propostos. Assim, na ausência de conceitos como esses, a análise seria quase vazia do ponto de vista da Linguística do Discurso ${ }^{16}$, graças à relação de interdependência entre esta e a Linguística do Sistema. Isso significa que restaria uma análise sociológica combinada a uma frágil análise linguística. Nessa perspectiva, nota-se que, uma vez que os textos inscritos nas gravuras são relacionados ao assunto educação, seria quase inevitável não apontar questões ortográficas, fonéticas, sintáticas ou mesmo uma compilação delas, haja vista que daí parte o efeito do clamor social.

Assim sendo, é o contexto de produção do discurso que fornece os subsídios analíticos necessários ao exame do objeto de estudo. Sem o contexto, os signos linguísticos são reduzidos a palavras soltas que mais servem de peças às estruturas normativas. Com ele, todavia, o signo linguístico, sendo signo ideológico, "vê-se marcado pelos horizontes social de uma época e de um grupo social determinado" (BAKHTIN, 2009, p. 45).

16. Para Koch (2012, p. 9), a Linguística do discurso é "uma linguística que se ocupa das manifestações linguísticas produzidas por indivíduos concretos em situações concretas, sob determinadas condições de produção".

\section{REFERÊNCIAS}

BAGNO, M. Nada na língua é por acaso: por uma pedagogia da variação linguística. São Paulo: Parábola Editorial, 2007.

BAKHTIN, M. M. Problemas da Poética de Dostoiévski. 5.ed. Rio de Janeiro: Forense Universitária, 2013.

BAKHTIN, M. M. (V. N. Volochínov). Marxismo e Filosofia da Linguagem. 13.ed. São Paulo: Hucitec, 2009.

CALVET, L. J. Sociolingüística: uma introdução crítica. 2.ed. São Paulo: Parábola, 2002.

DISCINI, N.; FIORIN, J. L. A linguagem humana: do mito à ciência. In: FIORIN, J. L. (org.). Linguística? 0 que é isso? São Paulo: Contexto, 2013

FARACO, C. A.. Linguagem \& diálogo: as ideias linguísticas do círculo de Bakhtin. São Paulo: Parábola Editorial, 2009.

FIORIN, J. L. A linguagem humana: do mito à ciência. In: FIORIN, J. L. (org.). Linguística? 0 que é isso? São Paulo: Contexto, 2013.

HANKS, W. F. Língua como prática social: das relações entre língua, cultura e sociedade a partir de Bourdieu e Bakhtin. São Paulo: Cortez, 2008.

ILARI, R.; BASSO, R. O português da gente: a língua que estudamos, a língua que falamos. São Paulo: Contexto, 2006.

$\mathrm{KOCH}, \mathrm{I} . \mathrm{G}$. V. A inter-ação pela linguagem. 11.ed. São Paulo: Contexto, 2012.

MAINGUENEAU, D. Análise de Textos de Comunicação. 3.ed. São Paulo: Cortez, 2004.

NICOLA, J.; INFANTE, U. Gramática Contemporânea da Língua Portuguesa. São Paulo: Scipione, 1997. 
NÓVOA, A. Os professores na Virada do Milênio: do excesso dos discursos à pobreza das práticas. Educação $\mathrm{e}$ Pesquisa, São Paulo, v.25, n.1, p.11-20, jan./jun. 1999.

ORLANDI, E. P. Análise de Discurso: Princípios e Procedimentos. 9.ed. Campinas: Pontes Editores, 2010.

PERINI, M. A. Para uma nova gramática do português. São Paulo: Ática, 1985.

SACCONI, L. A. Nossa Gramática - Teoria e Prática. 27.ed. São Paulo: Atual, 2001.
SEVERO, C. G. Linguagem e sociedade: algumas reflexões sobre determinismo. Working Papers em Linguística (UFSC), Santa Catarina, n.8, p.127-140, 2004.

SOARES, M. Linguagem e escola: uma perspectiva social. São Paulo: Ática, 1986.

WEEDWOOD, B. História concisa da Linguística. São Paulo: Parábola Editorial, 2002.
1. Mestrando em Cognição e Linguagem pela Universidade Estadual do Norte Fluminense Darcy Ribeiro (UENF), especialista em Língua Portuguesa pelo Centro Universitário Barão de Mauá (CBM) e graduado em Letras (Português/Literatura) pela Universidade Castelo Branco (UCB). Analista Judiciário e Professor da Escola de Administração Judiciária do Tribunal de Justiça do Estado do Rio de Janeiro (TJ-RJ). E-mail: so.thiago@hotmail.com 